\title{
Aplicación de un programa educativo en salud oral en adolescentes de una institución educativa peruana.
}

Rufasto-Goche $\mathrm{K}^{1}$, Saavedra-Alvarado $\mathrm{B}^{2}$. Aplicación de un programa educativo en salud oral en adolescentes de una institución educativa peruana. Rev Estomatol Herediana. 2012; 22(2):82-90

RESUMEN

Objetivos: Evaluar el efecto del programa educativo en salud oral en el nivel de conocimiento e índice de higiene oral en adolescentes en la Institución Educativa Nacional Nº1003 República de Colombia-Lima, Perú. Material y Métodos: El presente estudio comprende un ensayo clínico, prospectivo, analítico y longitudinal, en los adolescentes del $1^{\circ}$ a $5^{\circ}$ de secundaria de una Institución Educativa. Fueron evaluados 183 estudiantes sobre su higiene oral a los 0,90 y 180 días de la aplicación del programa; además los estudiantes fueron evaluados antes y después del programa sobre sus conocimientos de salud oral. El programa de salud bucal consistió en 10 sesiones educativas desarrolladas aplicando las técnicas expositivas, participativas y prácticas supervisadas sobre las estructuras de la cavidad oral, enfermedades orales más frecuentes, prevención en salud oral, alimentación balanceada y farmacodependencia. Para llevar a cabo el programa fue necesario utilizar materiales educativos didácticos orientados a promover el autocuidado y las medidas preventivas así como las tecnologías de la información y la comunicación. Para evaluar la higiene oral, fue empleado el índice simplificado de Greene-Vermillion y para medir los conocimientos adquiridos de los estudiantes fue aplicado un cuestionario validado. Resultados: el promedio del índice de higiene oral, a los 0 días fue de 2,54; después de 90 días de la aplicación del programa el promedio del índice de higiene oral fue de 1,77 y en el último control, que fue a los 180 días el promedio fue de 1,51. Conclusiones: Los índices de higiene oral y los conocimientos sobre salud oral fueron mejorados después del programa preventivo de salud oral $(\mathrm{p}=0,000)$, demostrando la importancia e influencia positiva de las actividades preventivas promocionales en los adolescentes. Palabras clave: SALUD BUCAL, EDUCACION EN SALUD DENTAL, ADOLESCENTES, ÍNDICE DE HIGIENE ORAL.

\section{Implementation of an oral health educative program in adolescents of an} Peruvian educational institution.

\section{SUMMARY}

Objectives: To evaluate the effect of oral health education program at the level of knowledge and oral hygiene index in adolescents at the National Educational Institution 1003 Republica de Colombia, Lima, Perú. Material and Methods: This study includes a clinical trial, prospective, longitudinal analytical, adolescents from 1 to 5 of secondary educational institution. 183 students were evaluated on their oral hygiene at 0,90 and 180 days after application of the program, students also were evaluated before and after the program on their knowledge of oral health. The program consisted of 10 oral health education sessions using the techniques developed expository, participatory and supervised practice on the structures of the oral cavity, most common oral diseases, oral health prevention, balanced diet and drug dependence. To carry out the program was necessary to use didactic educational materials aimed at promoting self-care and preventive measures as well as information technology and communication. To evaluate the oral hygiene index was used Greene-Vermillion simplified and to measure students' knowledge was applied a validated questionnaire. Results: The average oral hygiene index at 0 days was 2.53 , after 90 days of the implementation of the average rate was 1.77 hygiene oral and last control, which was at 180 days average was 1.51 . Conclusions: Rates of oral hygiene and oral health were improved after the oral health preventive program $(\mathrm{p}=0.000)$, demonstrating the importance and positive influence promotion of preventive activities in adolescents.

Key words: ORAL HEALTH, HEALTH EDUCATION, DENTAL, ADOLESCENT, ORAL HYGIENE INDEX .

\section{Introducción}

La placa bacteriana es considerada por la Organización Mundial de la Salud (OMS), como el factor etiológico fundamental de la caries y de las enfermedades periodontales $(1,2)$. Teniendo en cuenta esto, se puede entender la importancia que ocupa la higiene bucodental en la promoción y mantenimiento de la salud bucal (3).

Tanto las bacterias cariogénicas, como las periodontopatógenas se acumulan en la placa localizada a lo largo del margen gingival, de manera interproximal y en las fosetas y fisuras. La placa se acumula de manera más profusa en estas áreas específicas debido a que ninguna de estas localizaciones se expone de manera óptima a la acción autolimpiadora de la saliva, a la acción abrasiva de los alimentos o a la acción muscular de los carrillos y la lengua. El grosor de la placa disminuye conforme se aproxima a la superficie oclusal o incisal. A excepción de las cavidades y fisuras,

\section{Katherine Rufasto Goche ${ }^{1}$} Bernabé Saavedra Alvarado

Magister en Docencia e Investigación en Odontología, Facultad de Odontología. Universidad Nacional Federico Villarreal.

${ }^{2}$ Cirujano-Dentista. Facultad de Odontología. Universidad Nacional Federico Villarreal. Lima, Perú.

\section{Correspondencia}

Katherine Susan Rufasto Goche

Jr. Centenario 313 Breña, Lima, Perú.

E-mail: kathyrufasto5@hotmail.com en la superficie oclusal hay poca placa. Además la placa se forma más profusamente en los dientes mal posicionados o en aquellos con aplicaciones ortodónticas, en los cuales a menudo se dificulta el acceso para su limpieza.

El retiro diario de la placa no solo disminuye la posibilidad de caries dental; de igual importancia, es la posibilidad de retrasar el inicio de la gingivitis. Esto ocurre cuando los productos metabólicos finales de los microorganismos pa- 
tógenos contenidos en la placa pueden irritar los tejidos gingivales adyacentes y producen inflamación. Si la inflamación continúa, puede esperarse un sangrado después de realizar cualquier tipo de presión, por mínima que sea. Esta gingivitis puede ser detenida y revertida en las primeras etapas con técnicas adecuadas de cepillado, uso de hilo dental, en especial, si son acompañados de la orientación de un profesional (4).

Para controlar las enfermedades provocadas por la placa con métodos y técnicas disponibles, se ha hecho énfasis en las estrategias generales para reducir la caries:

\section{- Estrategias Generales}

- Control mecánico de la placa (cepillo dental, hilo dental, irrigador o enjuague).

- Control químico de la placa. Uso de fluoruros para inhibir la desmineralización y promover las remineralización; uso de agentes antimicrobianos para suprimir las bacterias cariogénicas.

- Disciplina con el azúcar.

- Uso de selladores de fosetas y fisuras, cuando estén indicados, en superficies oclusales de dientes posteriores.

\section{- Administrativos}

- Educación y promoción de la salud.

- Establecer acceso a centros dentales en donde se presten los servicios de diagnóstico, restaurativos y preventivos, y en donde las llamadas de recordatorio, planeadas con base en el riesgo sean rutinarias (4).

Cualquier programa de promoción de la salud bucal en niños y jóvenes debe incluir recomendaciones para obtener el control adecua- do de placa (5).

La placa bacteriana fermenta almidones y azúcares produciendo ácidos orgánicos. Estos ácidos desmineralizan el esmalte dental. Estas bacterias se incrementan en un ambiente ácido (6). Es necesario generalizar programas de prevención de la caries dental en las escuelas que incluyan actividades de educación nutricional en relación con los alimentos cariogénicos.

En el Reino Unido, The Committee on Medical Aspects of Food and Nutrition Policy (COMA) estableció que los azúcares son un importante factor dietético en la formación de la caries dental. Los padres necesitan conocer la necesidad de cambiar la dieta de sus hijos, querer realizarla y creer que pueden realizarla (7-9).

La correlación positiva entre consumo de azúcares y caries dental encuentra sustentación en el estudio clásico de Gustafson, en Vipelhom, Lund, Suecia (8-11), en él, quedó demostrado que más importante que la cantidad de azúcares ingeridos es su consistencia y frecuencia $(12,13)$

La importancia de la odontología preventiva y de la promoción de la salud para conseguir una mejora de la calidad de vida es fundamental (14). Estas acciones tienen como propósito reforzar las medidas básicas más importantes como la higiene bucal, la alimentación adecuada y la eliminación de hábitos nocivos (15).

La investigación realizada en países desarrollados y en desarrollo ha demostrado que los programas de salud en las escuelas pueden reducir los problemas comunes de salud $(16,17)$, incrementar la eficiencia del sistema educativo y avanzar la salud pública, educación y desarrollo económico y social de cada nación, por los que son consideradas como una inversión segura para el futuro. En consecuencia, la escuela es un marco ideal para desarrollar actividades de aprendizaje a todos los niveles, lo que incluye hábitos relacionados con la salud oral (18).

La implementación del programa de salud en el ámbito escolar debe realizarse a partir de estas consideraciones previas:

\section{a) Adaptar el programa al centro en donde se va a desarrollar.}

Es necesario tener en cuenta, no solo el número de alumnos, sino también el grado de participación de los padres y madres, el número de profesores participantes en el programa y su grado de compromiso, el grado y tipo de apoyo dado por el personal sanitario, etc. También es importante tener en cuenta aquellos servicios que ofrece el centro, que pueden afectar de una u otra manera el programa de higiene bucodental, especialmente la existencia de un comedor escolar, cafetería, kiosco escolar, etc.

b) Consensuar entre todos los sectores de la comunidad educativa y entre ésta y los agentes externos el desarrollo del programa (19).

Difusión, discusión y apropiación del programa por parte del equipo de trabajo y de la comunidad académica, para la comprensión de los objetivos, el método de trabajo, los alcances, limitaciones y responsabilidades de los participantes (20). 
El equipo directivo y el profesorado del centro deben informar al personal sanitario de las características de la Institución Educativa e informarles de las situaciones que pueden favorecer o dificultar el adecuado desarrollo del programa (19).

c) Planificar la implantación, desarrollo y evaluación del programa.

Esto significa tomar decisiones sobre: Documentos educativos en donde se incluye el programa de salud bucodental; temporalizar su desarrollo: inicial y final, número de horas a la semana, etc.; el profesorado que lo llevará a la práctica y quién será el responsable del centro que elaborará el informe final sobre el desarrollo del programa; delimitar el grado de implicación de padres y madres, personal sanitario, etc. (19). Según la OMS, la adolescencia transcurre desde los 10 hasta los 19 años (21).

El Ministerio de Salud del Perú (MINSA), indica que la población adolescente y joven representa más de la tercera parte de la población total del Perú $(31,7 \%)$ razón por la cual nuestro país es considerado como una nación de adolescentes y jóvenes, que a partir de algunos años contará con mayor población en edad de trabajo. De esta manera, si los gobiernos invierten ahora en salud y educación para sus jóvenes, cuando estos se integren a la fuerza laboral, su productividad contribuirá al incremento significativo de los niveles del Producto Global Interno (22).

La OMS estima que $70 \%$ de las muertes prematuras en el adulto se deben a conductas iniciadas en la adolescencia. Las principales cau- sas de morbilidad identificada en las y los adolescentes son las infecciones de las vías respiratorias superiores $(24,67 \%)$, seguidas por las enfermedades de la cavidad bucal $(14,31 \%)(23)$.

En odontología, los adolescentes son un grupo de referencia importante, pues en este periodo ocurren las principales variaciones dentales-maxilares y se consolida la identidad que definirá una actitud hacia la salud oral en el futuro. En relación con la salud oral, la incidencia de caries y enfermedad periodontal aumenta durante estos años. Además, es importante considerar el impacto directo que tiene la salud en el potencial educativo de adolescentes y jóvenes $(22,24,25)$.

En este sentido, Noborikawa, en el año 2004 realizó un ensayo de campo cuyo propósito fue evaluar la influencia del Programa Educativo de Salud Oral Sonrisas en una población de adolescentes peruanos del colegio "La Unión" del distrito de Pueblo Libre, Lima (26); fueron evaluados 132 alumnos de $1^{\circ}$ y $2^{\circ}$ secundaria a los cuales se les midió la higiene oral antes y después del programa. Se impartieron charlas sobre las estructuras de la cavidad oral, enfermedades orales más frecuentes y prevención en salud oral para lo cual se preparó un CDROM con los contenidos pertinentes. Para evaluar la higiene oral, fue empleado el índice simplificado de higiene oral de Greene-Vermillion y para medir los conocimientos adquiridos de los estudiantes fue aplicado un cuestionario. El nivel de higiene oral de los adolescentes mejoró al finalizar el programa, las mujeres presentaron significativamente menores niveles de placa bacteriana que los varones, tanto antes como después del programa y el nivel de conocimientos de los mismos se incrementó. Los resultados demostraron que los programas educativos diseñados con métodos creativos y novedosos dan resultados positivos en adolescentes.

Gutiérrez y col. en el 2005 determinaron el efecto en la actitud para la preservación de la salud bucal en la Institución Educativa de nivel primario en el distrito de San Martín de Porres, Lima (20). Aplicaron dos métodos didácticos: uno lúdico basado en juego de reglas y el otro expositivo por experto utilizando una maqueta y rotafolio. Se hicieron 8 sesiones, una por semana, de 45 minutos cada una. Se estableció la actitud en tres componentes: uno cognitivo; otro afectivo y el volitivo. Se evaluó la higiene oral antes y después de la experiencia. Los resultados indicaron que ambos métodos didácticos permiten incrementar el grado de conocimiento e información del alumnado.

Franco et al. en el 2005 ejecutaron un programa de intervención comunitaria, familiar e individual, orientado a la promoción de la salud general y bucal, en el municipio de Bello Antioquía, Medellín, la población estuvo conformada por 110 alumnos con edades comprendidas entre los 4 y 9 años, 8 profesores y la Asociación de Padres de Familia (27). El programa se realizó en tres fases: diagnóstica, intervención y evaluación de los resultados alcanzados. Lográndose la sensibilización de la comunidad educativa (profesores y estudiantes) sobre la importancia de la salud bucal, otro asunto importante fue el desarrollo de destrezas para un buen cepillado y la reducción de valores del índice de higiene oral, realizando fichados mensuales, en los cuales se valoraba la cantidad de placa presente.

Sánchez y col. en el año 2006 constituyeron una Escuela de Salud 
en el CEIP Los Álamos, los temas objeto del proyecto fueron: salud bucodental, alimentación y contexto higiénico del centro escolar (28). El equipo coordinador del proyecto elaboró una encuesta para valorar la situación del centro educativo antes de la experiencia respecto a los temas objeto de estudio. El profesorado preparó las unidades didácticas para su aplicación de forma globalizada. La salud bucodental se trabajó con actividades diversas: cuentos, poemas, canciones, dibujos, prácticas de cepillado. Los resultados obtenidos fueron muy positivos en salud bucodental y contexto higiénico, y, moderadamente positivos en alimentación.

Dávila M y col. en el 2008 realizaron una investigación cuasiexperimental dirigida a medir el nivel de conocimiento sobre enfermedades de la cavidad bucal y medidas preventivas que tienen los estudiantes antes y después de la aplicación de un programa educativo(29). La población estuvo conformada por 85 estudiantes del Municipio Iribarren del estado Lara, Venezuela. Se utilizaron estrategias como los juegos didácticos, simulaciones, demostraciones, videos, charlas y dibujos. Al analizar los resultados, el nivel de conocimiento mejoró considerablemente, siendo que el $66 \%$ de los escolares reportó un conocimiento bueno después de suministrar el programa educativo. Sobre la base de los resultados concluyeron que el programa educativo facilitó el aprendizaje sobre las enfermedades de la cavidad bucal y medidas preventivas en los escolares. En este estudio valoraron como muy positivo la participación de los padres del alumnado puesto que la presencia de ellos en el proyecto fue necesaria para la modificación de hábitos así como la participación de todo el profesorado.

Según el estudio epidemiológico "Prevalencia nacional de caries dental, fluorosis del esmalte y urgencia de tratamiento en escolares de 6 a 8, 10,12 y 15 años, Perú. 2001-2002"; realizado por el Ministerio de Salud, la prevalencia nacional de caries dental en los escolares de 10,12 y 15 años fue 90,4\% y el promedio de dientes cariados, obturados y perdidos en piezas permanentes de los escolares de 10, 12 y 15 años a nivel nacional fue 2,34. El promedio del CPO-D se incrementó conforme avanzó la edad, a los diez años 2,11; a los doce años 3,67 y a los quince años 5,90 (30).

Estos indicadores nos permiten apreciar en forma general la severidad de la caries dental en los escolares peruanos, que evidencia una necesidad de crear y fortalecer programas de prevención de salud oral en las instituciones educativas.

El objetivo de la presente investigación fue evaluar el nivel de conocimiento e índice de higiene oral según el efecto del programa preventivo en salud bucal en adolescentes de ambos sexos en la Institución Educativa Nacional No 1003 República de Colombia. Lima, Perú. Asimismo fomentará la adquisición de hábitos saludables de la Comunidad Educativa.

\section{Material y Métodos}

El presente estudio representó un ensayo clínico, prospectivo, analítico y longitudinal.

La población de estudio estuvo conformada por todos los alumnos de la Institución Educativa Nacional No1003 República de Colombia del distrito de Breña en Lima , Perú, que estuvo representada por 347 alumnos: 162 alumnos de nivel primaria y 185 de nivel secundaria.

La muestra quedó conformada por 183 alumnos de $1^{\circ}$ a $5^{\circ}$ de secundaria que cumplieron con los criterios de selección. El grupo de estudio estuvo constituido por 97 alumnos del $1^{\circ}$ a $5^{\circ}$ de secundaria pertenecientes a las secciones $\mathrm{A}$, quienes si recibieron el programa educativo. El grupo control estuvo constituido por 86 alumnos del $1^{\circ}$ a $5^{\circ}$ de secundaria pertenecientes a las secciones $\mathrm{B}$, quienes no recibieron el programa educativo. Asimismo de los 183 adolescentes 133 fueron de sexo masculino y 50 de sexo femenino con un edad promedio de 14,4 años.

El Programa de Salud Bucal se llevó a cabo en 6 meses comprendidos dentro del año escolar desde el $1^{\circ}$ de abril al $1^{\circ}$ de octubre del 2010 y consistió en 10 sesiones educativas desarrolladas en charlas, exposiciones dialogadas, ponencias, talleres, dinámicas de grupo, con temas acerca de las estructuras normales del sistema estomatognático, enfermedades orales más frecuentes, alimentación balanceada y farmacodependencia.

El Programa de Salud Bucal fue realizado de la siguiente manera:

Primera etapa: Semana 1 (del 29 de marzo al 04 de abril): Presentación y aceptación del programa por parte de la Institución Educativa (Director, profesorado y alumnos) y las familias.

Segunda etapa: Semana 2,3 y 4 (del 05 de abril al 25 de abril): Luego de evaluar la condición inicial de placa bacteriana mediante el índice de higiene oral simplificado de Greene y Vermillion, se tomó una prueba de entrada sobre el nivel de conocimientos de salud bucal a través de un cuestionario. En la población se evaluó el grado de conocimiento sobre: Funciones de la boca, enfermedades más comunes de la boca, causas de la caries 
dental, consecuencias de la caries dental y las medidas de prevención de la caries dental.

Tercera etapa: Semana 5 a 14 (del 26 de abril al 04 de julio): $1^{\text {a }}$ Sesión educativa: Ambientación de las aulas con material educativo. Teórica Multimedia: Introducción. Generalidades. Placa Bacteriana. Enfermedades de la cavidad bucal. $2^{\mathrm{a}}$ Sesión educativa: Teórica: Funciones de la boca. El diente y sus partes. Tipos de dentición: dentición temporal y dentición permanente. Control de placa. Instrucción de higiene oral. $3^{\mathrm{a}}$ Sesión educativa: Taller: Guía para una buena salud bucal-Colgate. Practica de técnica de cepillado con maquetas. $4^{\text {a }}$ Sesión educativa: Tríptico: Halitosis. $5^{\circ}$ sesión educativa: Teórica multimedia: Fluoruros y saliva

Cuarta Etapa: Semana 15 y 16 (del 05 de julio al 19 de julio): Evaluación de la placa bacteriana a los 90 días de la aplicación del programa.

Quinta etapa: Semana 17 a 26 (del 20 de julio al 26 de septiembre): $6^{a}$ Sesión educativa: Teórica: Alimentos cariogénicos. $7^{\text {a }}$ Sesión educativa: Taller: Alimentación balanceada. $8^{a}$ Sesión educativa: Díptico: Enjuagues bucales. 9a Sesión educativa: Taller: Reforzamiento de la técnica de cepillado. $10^{\mathrm{a}} \mathrm{Se}-$ sión educativa: Taller: Farmacodependencia y su impacto en la sociedad. Cáncer oral.

Sexta etapa: Semana 27 (del 27 de septiembre al 03 de octubre): Evaluación de la condición final de la placa bacteriana y evaluación final de conocimiento de salud bucal (a los 180 días de la aplicación del programa).

Para lograr los objetivos señalados se utilizaron los siguientes procedimientos pedagógicos: explicación, ejemplos y análisis de casos, lectura comentada, diálogo, modelamiento, discusión grupal.

Para medir el nivel de conocimientos se utilizó un cuestionario sobre prevención en salud oral de 10 preguntas. Este cuestionario se aplicó a los 0 días y 180 días del programa preventivo de salud bucal.

Para medir el registro de placa bacteriana se utilizó el índice de higiene oral de Greene y Vermillion; el intervalo de tiempo de las evaluaciones fue: la basal, a los 0 días del programa preventivo de salud bucal; la intermedia, a los 90 días de la intervención y la final, a los 180 días de aplicado el programa preventivo de salud bucal.

Se solicitó la autorización correspondiente al director del colegio donde se realizó el estudio, además se envió la carta de consentimiento informado a los padres para la aprobación de la participación de su hijo en el estudio. Al inicio del estudio se solicitó el asentimiento del propio adolescente de estudio. Los cuestionarios que se utilizaron para medir los conocimientos en higiene oral de los adolescentes fueron anónimos. Se utilizaron códigos para parear los cuestionarios entre los tiempos de evaluación.

Para el análisis se presentan valores como las medias con sus respectivas desviaciones estándares y los intervalos de confianza. Para comparar el nivel de higiene oral a los 0, 90 y 180 días de la aplicación del programa preventivo en salud bucal se utilizó la prueba ANOVA por cumplir con el supuesto de normalidad.

Para comparar el nivel de higiene oral a los 0,90 y 180 días de la aplicación del programa preventivo en salud bucal entre el grupo de estudio y el grupo control se utilizó la prueba $t$ student para muestras independientes. Para comparar el nivel de higiene oral a los $0,90 \mathrm{y}$ 180 días de la aplicación del programa preventivo en salud bucal estratificado según sexo se utilizó la prueba $t$ student para muestras independientes. Para la comparación del nivel de conocimientos del total de la población antes y después de la aplicación del programa preventivo en salud bucal se utilizó la prueba de Rangos Asignados de Wilcoxon. Para la comparación del nivel de conocimientos antes y después de la aplicación del programa preventivo en salud bucal entre el grupo de estudio y el grupo control se utilizó la prueba de rangos asignados de Wilcoxon.

Para la comparación del nivel de conocimientos antes y después de la aplicación del programa preventivo en salud bucal estratificado según sexo se utilizó la prueba de rangos asignados de Wilcoxon.

\section{Resultados}

El promedio de los índices de higiene a los 0 días fue de 2,54, luego de haber aplicado el programa preventivo de salud bucal (a los 90 días) el promedio de los índices de higiene oral fue de 1,77 y en el último control, el promedio del índice de higiene oral fue de 1,51. Se observa sus respectivas desviaciones estándares, existiendo diferencia estadísticamente significativa al aplicar la prueba ANOVA $(p=0,000)$ (Tabla 1).

El promedio de los índices de higiene oral en el grupo que se aplicó el programa preventivo de salud bucal (estudio), a los 0 días fue de 2,588, luego a los 90 días fue de 1,1534 y finalmente a los 180 días fue de 0,6587, esta diferencia de promedios resultó ser altamente significativa (Gráfico 1). El promedio de los índices de higiene oral en 
Tabla 1. Comparación del nivel de higiene oral en adolescentes a los 0,90 y 180 días de la aplicación del programa preventivo en salud bucal.

\begin{tabular}{lccccc}
\hline Controles & $\mathrm{N}$ & Media & D.Standar & Anova & Sign. \\
\hline 0 días & 183 & 2,5369 & 0,37331 & & \\
90 días & 183 & 1,7747 & 0,75955 & 11,616 & 0,000 \\
180 días & 183 & 1,5125 & 0,96997 & & \\
& & & & & \\
\hline
\end{tabular}

*Prueba ANOVA $(\mathrm{p}=0,000)$

Gráfico 1. Nivel de higiene oral en adolescentes a los 0,90 y 180 días entre el grupo de estudio y el grupo control.

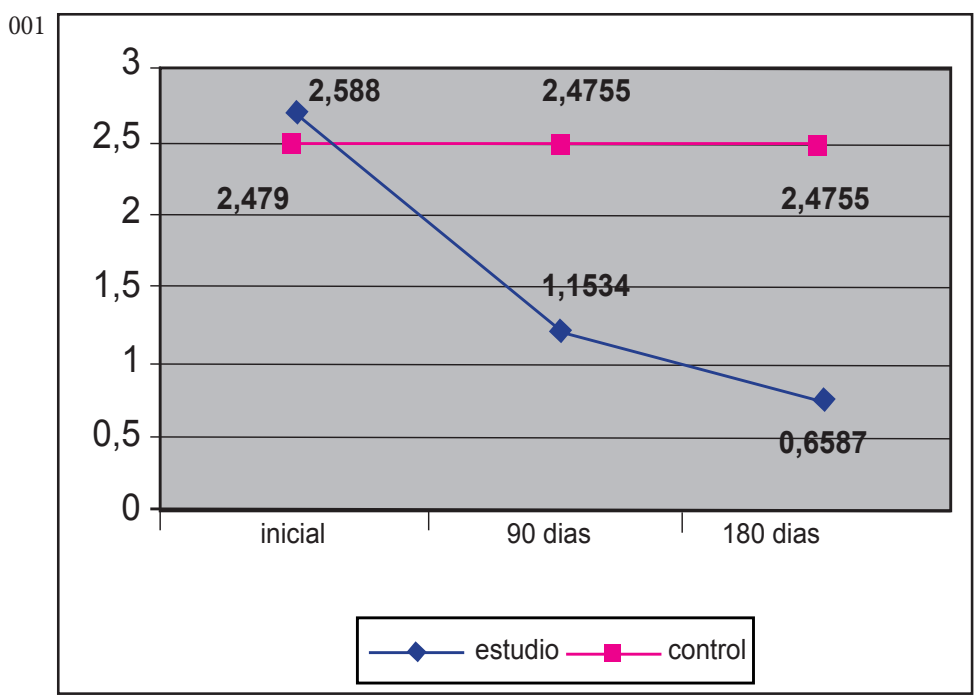

Tabla 2. Comparación del nivel de higiene oral en adolescentes a los 0 días de la aplicación del programa preventivo en salud bucal, según sexo.

\begin{tabular}{cccccc}
\hline Sexo & N & Media & D.Standar & T student & Sig. \\
\hline Masculino & 133 & 2,6570 & 0,30637 & 8,319 & 0,000 \\
Femenino & 50 & 2,2176 & 0,34869 & & \\
\hline
\end{tabular}

*Prueba t student para muestras relacionadas $(\mathrm{p}=0,000)$

Tabla 3. Comparación del nivel de higiene oral en adolescentes a los 180 días de la aplicación del programa preventivo en salud bucal, según sexo.

\begin{tabular}{lccccc}
\hline \multicolumn{1}{c}{ Sexo } & N & Media & D.Standar & T student & Sig. \\
\hline Masculino & 133 & 1,6303 & 0,99117 & 2,727 & 0,007 \\
Femenino & 50 & 1,1990 & 0,84269 & & \\
\hline
\end{tabular}

*Prueba t student para muestras relacionadas $(\mathrm{p}=0,007)$

Tabla 4. Comparación del nivel de conocimiento en adolescentes, antes y después de aplicar el programa preventivo en salud bucal, según puntaje.

\begin{tabular}{lcccc}
\hline & \multicolumn{2}{c}{ Antes } & \multicolumn{2}{c}{ Después } \\
Puntaje & F & $\%$ & F & $\%$ \\
\hline Bajo & 39 & 21,3 & 21 & 11,5 \\
Regular & 144 & 78,7 & 83 & 45,4 \\
Alto & - & - & 79 & 43.2 \\
TOTAL & $\mathbf{1 8 3}$ & $\mathbf{1 0 0}$ & $\mathbf{1 8 3}$ & $\mathbf{1 0 0}$
\end{tabular}

Wilcoxon: $-8,653$

p: 0,000 el grupo que no se aplicó el programa preventivo de salud bucal (control), a los 0 días fue de 2,479, luego a los 90 días fue de 2,4755 y finalmente a los 180 días se mantuvo constante (Gráfico 1).

El promedio de los índices de higiene oral a los 0 días en los adolescentes de sexo masculino fue de 2,66 y en los adolescentes de sexo femenino fue de 2,22 , existiendo diferencias estadísticamente significativas al aplicar la $t$ de student para muestras independientes $(\mathrm{p}=0,000)$ (Tabla 2).

El promedio de los índices de higiene oral a los 180 días en los adolescentes de sexo masculino fue de 1,63 y en los adolescentes de sexo femenino fue de 1,20; existiendo diferencias estadísticamente significativa al aplicar la $\mathrm{t}$ de student para muestras independientes $(\mathrm{p}=0,007)$ (Tabla 3$)$.

El nivel de conocimiento de salud bucal antes de iniciar la aplicación del programa educativo en salud oral, el conocimiento estuvo en un $78,7 \%$ (144 alumnos) y en un $21,3 \%$ (39 alumnos) el conocimiento de salud bucal estuvo en nivel bajo. Sin embargo luego de aplicar el programa de salud bucal el nivel de conocimiento sobre prevención en salud bucal estuvo en porcentajes altos entre el nivel de conocimiento alto 43,2\%(79 alumnos) seguido del nivel de conocimiento regular que fue de $45,4 \%$ (83 alumnos) (Tabla 4).

\section{Discusión}

En higiene oral; los promedios de los índices de placa bacteriana hallados en los adolescentes a los 0 días del programa fue de 2,54, a los 90 días fue de 1,77 y a los 180 días fue de 1,51, que nos indica que el programa tuvo efectos beneficiosos en los adolescentes, porque 
mejoraron significativamente su higiene oral al finalizar el programa $(\mathrm{p}=0,000)$.

Estos resultados son corroborados por investigaciones previas como la de Noborikawa que al aplicar un programa de salud en una población de adolescentes obtuvo los promedios del índice de placa bacteriana antes de aplicado el programa de 2,18 y después del mismo fue de 0,85 , encontrándose diferencias estadísticamente significativas $(\mathrm{p}=0,001)(26)$.

Así mismo Franco y col. mediante estrategias educativas dirigidas a los alumnos, padres y maestros a través de un programa de salud general y bucal, obtuvieron un mejor desarrollo de destrezas para un buen cepillado, trabajo que fue monitoreado por un higienista, algunos profesores y por los investigadores logrando una disminución importante en los índices de placa a lo largo del programa (27). Los resultados evidenciaron que en la primera y segunda medición se encontraron valores elevados de placa dental (cerca del 90\%) mientras que en el último control se evidenció una reducción importante del indicador.

Gutiérrez y col. al realizar una intervención educativa con dos métodos didácticos: al grupo A se le asignó el método didáctico expositivo por experto y al grupo B se le aplicó el método didáctico, utilizando un juego como estrategia de aprendizaje, obtuvieron los siguientes resultados: la higiene bucal en el grupo A al inicio de la intervención fue regular en un $22,3 \%$ y la higiene bucal en el grupo B fue regular en un $20,6 \%$, y al término de la intervención el grupo A tuvo una higiene bucal regular en un $52,7 \%$ y el grupo B obtuvo una higiene regular en un $88,4 \%$ y bue- na en un 8,82\% (20).

En conocimientos se observó que la enseñanza impartida por el programa preventivo de salud bucal fue mejorando los niveles de conocimientos en los adolescentes, siendo que al inicio del programa $0 \%$ de adolescentes tenían un nivel alto de preguntas respondidas correctamente, produciéndose un incremento estadísticamente significativo después del programa de salud oral $(43,2 \%)$, que nos indica que las sesiones educativas con información sobre salud bucal puede ser asimilada fácilmente por el alumno, siendo adecuado los medios utilizados para este fin. $(p=0,000)$.

Franco y col. lograron también la incorporación de nuevos saberes de promoción de la salud en los alumnos al finalizar un programa incorporando aprendizajes para una vida sana (27).

Dávila y col. obtuvieron resultados positivos mejorando el nivel de conocimiento de los escolares después de la aplicación de un programa educativo (30)(29). Antes de la intervención educativa los escolares tuvieron un $14 \%$ de nivel de conocimiento bueno sobre las enfermedades de la cavidad oral, al finalizar el programa educativo varió a $66 \%$, observándose diferencia estadísticamente significativa ( $p=0,001)$, concluyendo que existe la necesidad de implementar y fortalecer programas educativos dirigidos a la población escolar a fin de mejorar su calidad de vida y a modificar hábitos.

Así mismo, Sánchez y col. durante el desarrollo del proyecto escuela de salud elaboraron una encuesta para valorar la situación del centro antes de la experiencia respecto a los temas salud bucodental, contexto higiénico y alimentación (28). Los resultados obteni- dos fueron muy positivos en salud bucodental y contexto higiénico y moderadamente positivos, los conseguidos en alimentación.

\section{La higiene oral con relación al sexo}

Los promedios de los índices de placa bacteriana estratificados según el sexo, se observa que el de las mujeres fue de 2,21 y el de los varones 2,65 antes del programa preventivo de salud bucal. Después del programa los promedios de las mujeres descendieron a 1,20 y los varones a 1,63 donde se observa que ambos tuvieron una mejoría en los niveles de higiene oral, pero las mujeres obtuvieron aún mejor resultados, concluyendo que las mujeres lograron obtener una mejor receptividad y aprovechamiento del programa con las técnicas educativas utilizadas.

En este aspecto se coincide con Noborikawa halló que los promedios de los índices de placa bacteriana antes del programa educativo en las mujeres fue de 2,13 y en los varones 2,21, indicando que fueron grupos homogéneos al inicio del estudio. Al finalizar el programa, los promedios de las mujeres disminuyeron a 0,74 y los varones 0,94 coincidiendo con el presente estudio porque ambos sexos lograron resultados positivos, siendo también que las mujeres obtuvieron una mejor higiene oral (26).

En conocimientos, se observa que antes del programa, las mujeres y los varones tuvieron $0 \%$ de respuestas de puntaje alto en el cuestionario, esto significa que ambos tenían igual conocimiento de salud oral al inicio del estudio. Luego se observó que los porcentajes fueron para las mujeres de 92,86 en puntaje alto y para los varones $76,81 \%$, determinando que las mujeres fueron las que tuvieron un mayor co- 
nocimiento después del programa y mejor adquisición de hábitos saludables.

Datos corroborados en el trabajo de Noborikawa en donde se observó que antes del programa las mujeres tuvieron un promedio de $67,3 \%$ de respuestas correctas en el cuestionario y los varones al inicio del estudio (26). Luego nuevamente se observa que los porcentajes promedios de respuestas correctas después de aplicado el programa las mujeres obtuvieron un porcentaje promedio de respuestas correctas de $78,6 \%$ y los varones obtuvieron un $70 \%$ donde también se encontró diferencias significativas $(\mathrm{p}=0,003)$.

Finalmente es de suma importancia resaltar que los efectos positivos de las intervenciones educacionales tienden a ser considerados transitorios en el tiempo, con la consiguiente desaparición de los beneficios observados en un plazo corto; sin embargo mejorías en el tiempo se pueden obtener con el refuerzo o repetición de la intervención educativa enseñando dentro de grupos líderes pre-existentes y minimizando las potenciales barreras dentista- paciente, sensibilizando a la comunidad educativa que son los profesores y estudiantes sobre la importancia de la salud bucal, posicionando los hábitos de higiene bucal en la cotidianidad de la escuela, reduciendo los valores del índice de higiene oral, mediante la atención a las necesidades básicas de salud, así como el aprendizaje de los estudiantes de odontología sobre las características y el compromiso que requiere el trabajo comunitario.

Concluimos que el nivel de higiene oral de los adolescentes de la institución educativa mejoró progresivamente durante la aplicación del programa preventivo en salud bucal, con diferencias estadísticamente significativas. Así mismo el promedio del índice de higiene oral fue disminuyendo progresivamente en el grupo de estudio, sin embargo en el grupo control el promedio del índice de higiene oral se mantuvieron constantes. Las adolescentes presentaron significativamente menores niveles de placa bacteriana después de la aplicación del programa preventivo de salud bucal.

El nivel de conocimiento de los adolescentes mejoró a los 180 días de la aplicación del programa preventivo en salud bucal, teniendo un alto porcentaje de escolares con niveles de conocimientos altos, puntuación que no fue registrada antes de la aplicación del programa.

El nivel de conocimiento mejoró en el grupo de estudio, teniendo que todos los adolescentes registraron un nivel de conocimiento alto al finalizar el programa.

El nivel de conocimientos fue significativamente más alto en las adolescentes que en los adolescentes al concluir el programa.

\section{Referencias Bibliográficas}

1. Van HJ. Profilaxis comunitaria, semicomunitaria e individual en niños y jóvenes. En: Van HJ, Stöckli PW. Atlas de Odontología Pediátrica. Barcelona: Masson; 2002.p. 133-150.

2. Perez A. La biopelícula: Una nueva visión de la placa dental. Rev Estomatol Herediana. 2005; 15(1):82-5.

3. Guedes AC, Santos EM. Higiene Bucodental en odontopediatría. En: Guedes AC. Rehabilitación bucal en odontopediatría integral. 3a Edición. Medellín: Corporación para Investigaciones Biológicas; 2003. p.63-74.

4. Harris NO. Introducción a la odontología preventiva prima- ria. En: Harris NO, García F. Odontología preventiva primaria. 2a Edición. México D.F: Manual Moderno; 2006. p.1-16.

5. Declerck D, Leroy R, Martens $\mathrm{L}$, et al .Factors associated with prevalence and severity of caries experience in preschool children. Community Dent Oral Epidemiol. 2008; 36 (2): 16878.

6. Palmer CA, Boyd LD. Nutrición, dieta y estado oral. En: Harris NO, García F. Odontología preventiva primaria. 2a Edición. México D.F: Manual Moderno; 2006. p.305-326.

7. Rodrigues de Almeida E, Guedes AC. Hábitos alimenticios en odontopediatría. En: Guedes Pinto AC. Rehabilitación bucal en odontopediatría integral. Medellín: Corporación para Investigaciones Biológicas; 2003.p.75-91.

8. Cleaton PE, Mobley C. Azúcar y otros edulcorantes. En Harris NO, García F. Odontología preventiva primaria. 2a Ed. México D.F: Manual Moderno; 2006. p.289-304.

9. Serra L. Dieta, nutrición y salud oral. En: Cuenca E, Baca-García P. Odontología Preventiva y Comunitaria: Principios, Métodos y Aplicaciones. Barcelona: Masson; 2003. p. 63-86.

10Bordoni N, Doño R. Squassi A, Bellagamba H, Pereyra L, Argentieri A. Odontología preventiva. Buenos Aire. Odontología Preventiva. Tercera Edición. Buenos Aires.: PRECONC/ PALTEX - OPS/OMS; 1999.p. 25-60

11.Escobar R. Prevención y control de las infecciones de origen dento-bacteriano. En: Cárdenas D. Fundamentos de odontología: Odontología pediátrica. 
Medellín: Corporación para investigaciones biológicas; 2003. p. 46-83.

12Manau C. Placa bacteriana. En: Cuenca E, Manau C. Odontología preventiva y comunitaria: Principios, métodos y aplicaciones. 2a Edición. Barcelona: Masson; 2002. p. 25-32.

13Lingström $\mathrm{P}$, Holm AK, Mejàre I, et al . Dietary factors in the prevention of dental caries: a systematic review. Acta Odontol Scan. 2003; 61: 331-40.

14.Cuenca E. Principios de la prevención y promoción de la salud en odontología. En: Cuenca Sala, E. y Baca García, P. Odontología Preventiva y Comunitaria: Principios, Métodos y Aplicaciones. 3a Ed. Barcelona: Masson; 2003. p. 1-18.

15 Garza AM. Control de Infecciones y Seguridad en Odontología. México D.F.: Editorial Manual Moderno S.A; 2007. p.1-14.

16.Collazos J, Mattos M, Carbajal C. Salud pública dental. En: Melgar RA. Principios en prevención de salud bucal. Lima: Asociación Peruana de Odontología Preventiva y Social; 2008.p. 9-44.

17.Romero J, Juarez ML. Prevalencia y factores de riesgo de la caries dental en escolares de ciudad Nezahualcóyotl. Med Oral. 2006; 8(4): 163-7.

18.Delgado E, Melgar R. Promoción de la salud. En: Melgar RA. Principios en prevención de salud bucal. Lima: Asociación Peruana de Odontología Preventiva y Social; 2008.p. 45-59.

19.Generalitat Valenciana, Conselleria de Sanitat. Programa de Salud Bucodental. Guía del Profesorado. Educación primaria. Valencia: Generalitat Valenciana; 2006. p. 1-70. (Citado el
6 Noviembre del 2009). Disponible en: http://publicaciones.san.gva.es/publicaciones/ documentos/V.1528-1999.pdf

20.Gutiérrez M, Ortiz L, Albino J, et al. Eficacia de dos métodos didácticos en la actitud del niño para la preservación de su salud bucal. Odontol Sanmarquina. 2007; 10(2): 8-11.

21.Gedler L. Los tiempos difíciles y la inteligencia emocional en el ejercicio odontológico. Acta Odont Venez. 2009; 47(2):1-5.

22. Maddaleno M, Morello P, Infante-Espinola F. Salud y desarrollo de adolescentes y jóvenes en Latinoamérica y el Caribe: desafíos para la próxima década. Salud Pública Mex. 2003; 45 (S1): 132-9.

23.Ministerio de Salud del Perú. Documento técnico análisis de salud de las y los adolescentes, ubicándolos y ubicándonos. Lima: MINSA; 2009.

24.Faisal M, Vila V. La educación como punto de partida inicial en la prevención (Internet). Corrientes: Comunicaciones científicas y tecnológicas de la Universidad Nacional del Nordeste; 2004. Citado en diciembre del 2011) Disponible en: http://www.unne.edu.ar/ unnevieja/Web/cyt/com2004/3Medicina/M-036.pdf

25.Rodríguez K, Salgueiro J, Díaz C, Rosales Álvarez. Nivel de conocimientos sobre educación para la salud en adolescentes del Politécnico "Pedro Téllez" de Pinar del Río, 2008. Rev Ciencias Médicas. 2010; 14(1): 3746.

26.Noborikawa AK. Influencia del programa educativo de salud oral sonrisas en una población de adolescentes peruanos. Rev Estomatol Herediana. 2009;
19(1):31-38.

27.Franco A, Martínez C, Álvarez $M$, et al. Los niños tienen la palabra: Nuestras bocas sanas para una vida sana. CES odontología. 2008; 21(1): 9-15.

28.Servicios Municipales de Salud. Boletín de Salud Comunitaria. Escuela de Salud. Experiencia en el CEIP Los Alamos (Internet). Murcia, España: Servicios Municipales de Salud; 2007. (Citado el diciembre del 2011) Disponible en: http://www. ayuntamientomurcia-salud.es/ WebOriginal/user/documentos/ boletin/boletin_comunidad_10. pdf

29.Dávila M, Mujica M. Aplicación de un programa educativo a los escolares sobre enfermedades de la cavidad bucal y medidas preventivas. Acta Odontol Venez. 2008; 46(3): 1-7.

30.Ministerio de Salud del Perú, Oficina General de Epidemiología. Estudio Epidemiológico. Prevalencia nacional de caries dental, fluorosis del esmalte y urgencia de tratamiento en población escolar de 6 a 8, 10, 12 y 15 años a nivel del país, año 2001-2002. Lima: MINSA; 2005 